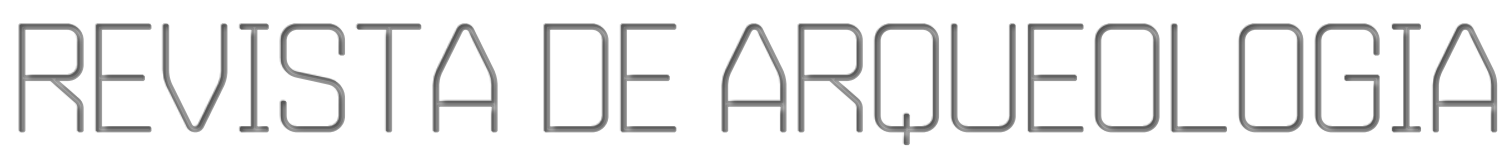

Volume 33 No. $3 \quad$ Setembro-Dezembro 2020

Edição Especial: Gestão de Acervos Arqueológicos

\title{
A FORMAÇÃO DA COLEÇÃO ARQUEOLÓGICA DO MUSEU DE PORTO ALEGRE JOAQUIM FELIZARDO E AS PRÁTICAS DE GESTÃO IMPLEMENTADAS
}

\section{Fernanda Bordin Tocchetto*}

RESUMO

Este artigo apresenta aspectos sobre a trajetória que resultou na formação da Coleção Arqueológica sob guarda do Museu de Porto Alegre Joaquim Felizardo, órgão da Secretaria Municipal da Cultura de Porto Alegre, e sobre as estratégias de gestão relacionadas à salvaguarda do acervo, relacionadas às áreas da arqueologia, conservação e museologia, desde seu início em 1993.

Palavras-chave: acervo arqueológico; gestão; museu.

\footnotetext{
* Servidora pública aposentada pela Prefeitura Municipal de Porto Alegre/RS, concursada para o cargo de professora; exerceu a função como arqueóloga, entre 1993 e 2019 no Museu de Porto Alegre Joaquim Felizardo, órgão da Secretaria Municipal da Cultura de Porto Alegre (SMC).

E-mail: fernandatocchetto@gmail.com. ORCID: http://orcid.org/0000-0002-1639-1291.
} 
THE FORMATION OF THE ARCHAEOLOGICAL COLLECTION OF THE PORTO

ALEGRE MUSEUM JOAQUIM FELIZARDO AND THE MANAGEMENT

PRACTICES IMPLEMENTED

\section{ABSTRACT}

This article presents aspects about the trajectory that resulted in the formation of the Archaeological Collection under Porto Alegre Museum Joaquim Felizardo custody, an organ of the Municipal Secretariat of Culture of Porto Alegre, and the management strategies concerning the safeguard of the collection, related to Archaeology, Conservation and Museology areas, since 1993.

Keywords: archaeological collection; management; museum.

\section{LA FORMACIÓN DE LA COLECCIÓN ARQUEOLÓGICA DEL MUSEO DE PORTO ALEGRE JOAQUIM FELIZARDO Y LAS PRÁCTICAS DE GESTIÓN IMPLEMENTADAS}

RESUMEN

Este artículo presenta aspectos sobre la trayectoria que resultó en la formación de la Colección Arqueológica bajo la custodia del Museo de Porto Alegre Joaquim Felizardo, órgano de la Secretaría Municipal de Cultura de Porto Alegre, y las estrategias de gestión relacionadas con la salvaguarda de la colección, vinculadas con las áreas de la Arqueología, Conservación y Museología, desde sus inicios en 1993.

Palabras clave: colección arqueológica; gestión; museo. 


\section{INTRODUÇÃO}

O Museu de Porto Alegre Joaquim Felizardo (Figura 1) é uma Instituição vinculada à Secretaria Municipal da Cultura de Porto Alegre $(\mathrm{SMC})^{1}$ e possui, sob sua guarda, diferentes tipos de coleções. Na época da sua criação pela Municipalidade, em 1979, eram constituídas por objetos tridimensionais e fotografias, destinando-se "(...) à divulgação do acervo reunido e das pesquisas realizadas sobre os elementos culturais em seu processo histórico na dinâmica espacial de Porto Alegre" (Decreto de Criação pela Prefeitura Municipal, no 6598, 13 de março de 1979)². Desde seu princípio, o referido Museu se dedicou a contar a história da cidade, incorporando um acervo dos séculos XIX e XX, preponderantemente relacionado a Porto Alegre, constituído por mobiliário, indumentária, instrumentos musicais, objetos de uso pessoal, de decoração, relacionados à vida doméstica, ao exercício de determinadas profissões, entre outros, bem como fotografias ${ }^{3}$.

Figura 1 - Museu de Porto Alegre Joaquim Felizardo. Fotografia: Guilherme Lund (s/d).

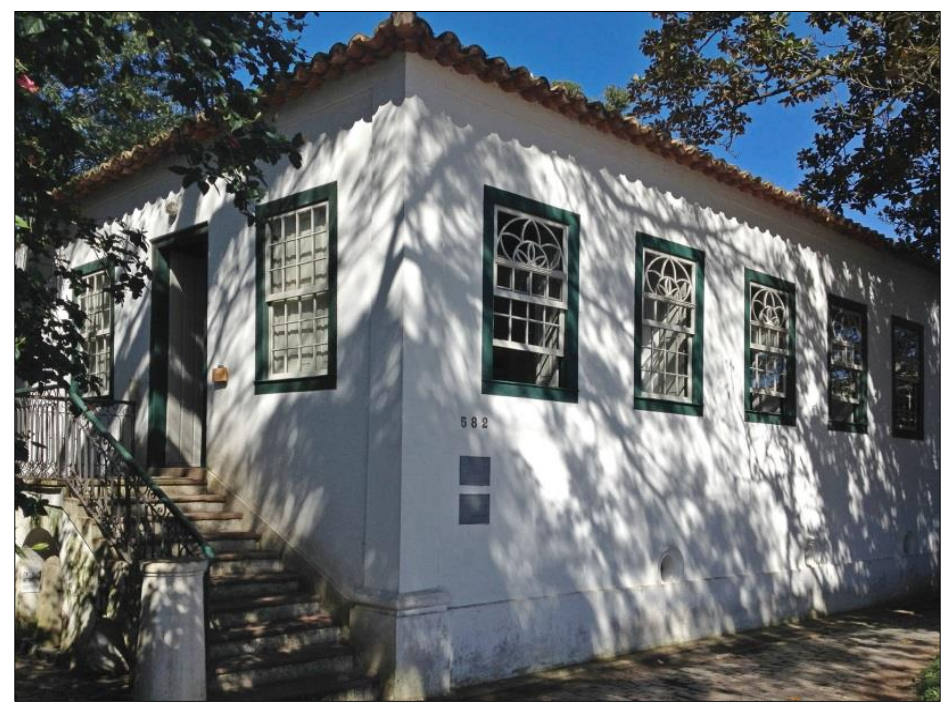

Já a formação do acervo arqueológico do Museu teve seu tímido início no final da década de $1980^{4}$, vindo a se constituir de forma sistemática e contínua a partir de 1993. Foi nesse ano que a Instituição passou a desenvolver, dentre suas ações, pesquisas arqueológicas no território municipal, iniciando a composição de um rico acervo majoritariamente com origem no espaço urbano. Atualmente a Coleção Arqueológica do museu é composta por mais de 250.000 objetos ${ }^{5}$ (entre inteiros e fragmentados) confeccionados em material cerâmico, lítico, ósseo, vítreo, metálico, em couro, louça, etc., além de remanescentes humanos, provenientes de 91 sítios e de ocorrências

\footnotetext{
${ }^{1}$ O Museu se localiza na Rua João Alfredo, 582, Bairro Cidade Baixa, Porto Alegre/RS.

2 Acessível em http://www.museudeportoalegre.com/documentos-2/. Data de acesso: 05/12/2020.

${ }^{3}$ Sobre o acervo, ver em http://www.museudeportoalegre.com/acervo-2/ (data de acesso: 05/12/2020). Sobre a história da Instituição, consultar Possamai (2001).

${ }^{4}$ A arqueóloga Vera Lucia Thadeu, quando Diretora do Museu de Alegre entre 1989 e 1993, coletou objetos arqueológicos durante a construção do Largo Glênio Peres, no Centro Histórico, e as intervenções realizadas no pátio do Solar Lopo Gonçalves, sede do Museu.

${ }^{5} \mathrm{O}$ Museu tem sob sua guarda, no espaço destinado à Reserva Técnica, 227.755 objetos. Dois grandes acervos recuperados nos sítios arqueológicos Praça Rui Barbosa e Santa Casa de Misericórdia, não contabilizados neste total, estão emprestados para o Museu de Ciências e Tecnologia da PUCRS e para o Centro Histórico Cultural Santa Casa, respectivamente, para fins de pesquisa.
} 
arqueológicas (OAs) referentes ao período pré-colonial e aos séculos XVIII, XIX e XX (desde suas primeiras grandes fazendas de produção agropastoril). Tais sítios e OAs são aldeias indígenas; quilombo urbano; unidades domésticas urbanas, fabris, religiosas, hospitalar; chácaras e fazendas; cemitério; logradouros (vias, praças); lixeiras coletivas (na antiga orla do lago Guaíba).

Principalmente a partir da década de 1990, em função de suas políticas e demandas, o Museu de Porto Alegre passou a se aproximar do conceito de Museu de Cidade, aspecto esse estimulado e reforçado pela pesquisa de sítios e acervos arqueológicos do Município. A missão da Instituição, como fica evidente em seu Regimento Interno, reforça o recorte territorial e a ênfase na história e memória de Porto Alegre: "A missão do Museu é promover a interação da sociedade com o patrimônio cultural do município, com ênfase na sua história e memória, através da preservação, pesquisa e comunicação dos bens culturais sob a guarda da Instituição" (PREFEITURA MUNICIPAL DE PORTO ALEGRE - SECRETARIA MUNICIPAL DA CULTURA, 2017) ${ }^{6}$.

Mais recentemente a Instituição passou a construir e a adotar uma abordagem mais inovadora e atual de museus de cidade, de modo que ela não seja entendida como voltada exclusivamente ao passado, servindo apenas como repositória da história de Porto Alegre, mas voltada ao seu presente, a sua diversidade e aos desafios e conflitos relacionados aos diferentes grupos sociais. Nesse sentido, nas gestões da Diretora Leticia Bauer ${ }^{7}$, passamos a construir, na prática, a ideia do “(...) Museu como lugar de observação, como lugar de escuta e como lugar de fala sobre Porto Alegre em seus diferentes tempos" (BAUER, 2018, p. 148), o que configura uma tentativa de conceituar a Instituição como uma plataforma contemporânea de reflexão sobre a cidade.

Considerando isso, o acervo arqueológico do Museu de Porto Alegre tem participado de exposições de curta duração, provocando reflexões sobre o momento presente, sobre a dinâmica cultural, sobre as ressignificações da cultura material e as diferentes identidades que compõe a cidade. Um exemplo disso são as inserções das presenças indígenas e afrodescendentes na exposição de longa duração, tendo como suportes vitrines e a maquete de Porto Alegre elaborada a partir da planta de 1839 .

Um acontecimento importante envolvendo o Museu em questão diz respeito aos Guarani em Porto Alegre. A Instituição registrou dezessete sítios e ocorrências arqueológicas pré-coloniais, sendo sete multicomponenciais associados a evidências dos séculos XVIII, XIX e XX, resultando em acervo salvaguardado pelo Museu e exposições sobre a ocupação indígena no território do Município. Em junho de 2019, três famílias Guarani Mbya se instalaram em parte de uma área privada situada na Ponta do Arado, Bairro Belém Velho, onde está previsto um condomínio de classe alta. No local onde estão vivendo, há um sítio arqueológico relacionado aos Guarani pré-coloniais, registrado junto ao IPHAN em 1993. Provavelmente também apoiados nessa informação, o grupo indígena afirma que a área faz parte de seu território tradicional e luta pela sua retomada. $\mathrm{O}$ assunto chegou às mídias e os canais de comunicação procuraram o Museu para gravar entrevistas e filmar os objetos encontrados no sítio. Esse é um exemplo do potencial que pode e deve ser explorado quanto à participação e contribuição do Museu em questões sociais a partir de suas pesquisas e acervos.

\footnotetext{
${ }^{6}$ O Regimento Interno do Museu de Porto Alegre Joaquim José Felizardo foi publicado no Diário Oficial de Porto Alegre (DOPA) em 08 de novembro de 2011. Acessível em http://www.museudeportoalegre.com/documentos-2/. Data de acesso: $05 / 12 / 2020$.

${ }^{7}$ Gestões da Diretora Leticia Brandt Bauer ocorridas entre 2015 e 2016 e de 2018 a 2020.
} 
Mas como se deu a formação da Coleção Arqueológica nos últimos 25 anos e o desenvolvimento, pelo Museu, de trabalhos sistemáticos com o patrimônio arqueológico, vindo a assumir um papel de gestor por um grande período?

Em 1993, eu exercia o cargo de professora na Secretaria Municipal da Educação (SMED) quando fui cedida para a SMC, passando a ocupar um lugar de trabalho no Museu. Nesse mesmo ano demos início às pesquisas arqueológicas com o objetivo de confirmar e estudar a presença indígena pré-colonial na área rural do Município. A Instituição deu total apoio às investigações que passaram a ser desenvolvidas por mim, como funcionária pública, e mais um grupo de arqueólogas/os, com bolsas recém-mestre da FAPERGS, e estagiárias/os ${ }^{8}$. Naquela época não tínhamos ideia de que, abaixo das camadas de asfalto e paralelepípedos, haveria potencial arqueológico relacionado aos períodos pré-colonial e aos séculos XVIII, XIX e XX. O uso intenso do solo urbano impactando a superfície e subsolo dos núcleos urbanos e suas periferias, onde a expansão é avassaladora -, bem como a pouca monumentalidade e visibilidade dos vestígios arqueológicos provocavam um descrédito em relação a sua preservação. Assim, de uma forma ingênua e apaixonada, fomos descobrindo novas possibilidades, e a arqueologia urbana surgiu aos nossos olhos com grande potencial para contribuir na construção da história da cidade a partir de suas materialidades. Era uma área nova para todos nós, considerando que os primeiros artigos versando sobre o tema no Brasil foram publicados por Cazzetta (1991) e Juliani (1993).

Já nos primeiros anos, diagnosticado o alto potencial arqueológico do Município, demandas de salvamentos arqueológicos em áreas públicas municipais - através de projetos de reformulação urbana de logradouros e, também, associados a projetos de restauração de bens imóveis -, de projetos do próprio Museu e de pós-graduação (mestrado e doutorado), bem como de ações educativas, levaram à tomada de encaminhamentos que viessem melhor estruturar e organizar a atuação da Instituição sobre o patrimônio arqueológico. Em 1997 foi criado o Programa de Arqueologia Urbana, visando à proteção, à valorização e à interpretação do patrimônio arqueológico de Porto Alegre (TOCCHETTO et al., 2000). Foram estabelecidos Termos de Cooperação Técnica entre o Museu/UFRGS e Museu/PUCRS, oportunizando a participação de acadêmicos nos trabalhos de campo e de laboratório, bem como o desenvolvimento de estudos em nível de pós-graduação e graduação na PUCRS e na UFRGS. Atualmente são vinte trabalhos concluídos - onze dissertações de mestrado ${ }^{9}$, seis teses de doutorado ${ }^{10}$, três trabalhos de conclusão de cursos de graduação e de especialização ${ }^{11}$, alguns deles resultando em livros ${ }^{12}$. Em sua grande maioria, as pesquisas foram voltadas à cultura material recuperada em sítios arqueológicos, a qual foi exaustivamente investigada e interpretada.

Apesar de estarmos, na época, mais voltada/os à pesquisa e à publicização dos seus resultados - através de exposições, ações educativas, publicações, participação em eventos científicos e realização de palestras -, as preocupações com a preservação do patrimônio arqueológico de Porto Alegre provocaram uma reorientação do nosso trabalho. Arqueologia em meios urbanos, considerando a constante transformação das

\footnotetext{
${ }^{8}$ Arqueólogas/os com bolsa recém-mestre da FAPERGS: Fabíola Silva, Francisco Noelli e Katya Vietta. Estagiárias/os: André Soares, João Felipe da Costa e Karla Marques.

${ }^{9}$ Symanski (1998), Thiesen (1999), Oliveira (2005), Santos (2005), Branchelli (2007), Bitencourt (2011), Lazzarotti (2013), Nunes (2014), Baretta (2015), Tatsch (2015), Fraga (2017).

10 Tocchetto (2004), Carle (2005), Thiesen (2005), Santos (2009), Company (2011), Baretta (2020).

${ }^{11}$ Baretta (2009), Moraes (2015), Alves (2017).

12 Symanski (1998), Oliveira et al. (2009), Tocchetto (2010). Tocchetto et al. (2001) foi um trabalho de pesquisa do próprio Museu, com acervos de dois sítios arqueológicos (lixeiras coletivas).
} 
suas paisagens, remete-nos a questões relacionadas a potencial arqueológico, a riscos de destruição e instrumentos de preservação. $\mathrm{O}$ vínculo indissociável entre arqueologia urbana e gestão está relacionado, principalmente, com a necessidade de uma tutela baseada no desenvolvimento de uma arqueologia preventiva. Cabe ao poder público implementar estratégias de proteção nos níveis jurídico e administrativo que visem à mitigação dos impactos decorrentes da dinâmica das cidades (TEMIÑO, 2004). Nessa direção, incluímos uma nova frente relacionada à gestão preventiva.

A partir do ano 2000, visando o cumprimento da Resolução CONAMA, de 1986, e preocupadas/os com os impactos que o patrimônio arqueológico de Porto Alegre vinha sofrendo em função do uso intenso do solo e ampliação da malha urbana,foi desencadeada uma forma de ação compartilhada entre a SMC, representada pelo Museu, a Secretaria Municipal do Meio Ambiente (SMAM) e o Instituto do Patrimônio Histórico e Artístico Nacional (IPHAN). Entre 2000 e 2009, o Setor de Arqueologia do Museu participou, junto à Coordenação do Licenciamento Ambiental da SMAM, dos processos de licenciamento ambiental do Município. Estava tendo início a relação do Museu com a arqueologia empresarial através do recebimento e guarda de acervos arqueológicos.

Essa nova frente teve desdobramentos, como a elaboração do Mapa Arqueológico de Porto Alegre (com os sítios e as ocorrências arqueológicas georreferenciadas), realizado pela Companhia de Processamento de Dados do Município de Porto Alegre (PROCEMPA) em parceria com o Museu, para ser utilizado como instrumento de gestão preventiva (TOCCHETTO, 2016); a inclusão de itens sobre o patrimônio arqueológico no Plano Diretor de Desenvolvimento Urbano e Ambiental de Porto Alegre; e o desenvolvimento de um software denominado Sistema de Gestão e Informação Arqueológica (SGEIA). Preocupações com a organização, preservação e disponibilização das informações geradas com os estudos arqueológicos em Porto Alegre, levaram-nos à constituição de um sistema informatizado através de uma parceria com a PROCEMPA. O SGEIA foi desenvolvido para proporcionar a documentação e a gestão pública das informações arqueológicas administradas pelo Museu, incluindo as relacionadas ao licenciamento ambiental.

A execução do Programa Monumenta, do Ministério da Cultura, com a parceria dos estados e municípios, também exigiu que o Museu se envolvesse na gestão das pesquisas em Porto Alegre a partir de 2006, gerando mais acervo a ser salvaguardado pela Instituição. Foram três projetos associados à restauração - a Praça da Alfândega, a Igreja Nossa Senhora das Dores e a Pinacoteca Municipal Rubem Berta. Com o Programa de Aceleração do Crescimento (PAC) das Cidades Históricas, continuamos dando apoio, principalmente com relação aos termos de referência.

A partir dessas práticas, o acervo arqueológico, principalmente urbano, foi crescendo. A inserção de pesquisas arqueológicas como condicionantes dos processos de licenciamento ambiental no Município levou ao crescimento do acervo de maneira vertiginosa. Em 2002 eram 22 sítios e ocorrências arqueológicas registradas, passando a $91 \mathrm{em} 2020^{13}$. O Museu, por muitos anos e por orientação do IPHAN, era a única Instituição que concedia endossos em nível municipal com o objetivo de centralizar os acervos e documentações do patrimônio arqueológico de Porto Alegre. Em vista dessa realidade, sentimos a necessidade de começar a regular a entrada de materiais arqueológicos e elaboramos, em 2010, o primeiro Termo de Responsabilidade para Concessão de Endossos Institucionais, como uma tímida iniciativa. Em 2011 foi contratado um arqueólogo pela Coordenação da Memória Cultural da SMC para trabalhar nos

13 Ver Relação de Sítios e Ocorrências Arqueológicas (OA) em Porto Alegre no site http://www.museudeportoalegre.com/documentos-2/. Data de acesso: 05/12/2020. 
procedimentos relacionados ao licenciamento ambiental, liberando o Museu dessa tarefa $^{14}$.

Aproveitando o momento de qualificação dos museus no cenário nacional e constatando que uma nova demanda estava surgindo para as instituições acadêmicas e de pesquisa que se dedicavam a investigações arqueológicas e/ou que concediam endossos institucionais a projetos, resolvemos dirigir um olhar mais acurado à gestão dos materiais sob guarda do Museu. Estavam se intensificando as relações entre a arqueologia e a museologia, as quais tiveram início com a museóloga Maria Cristina Oliveira Bruno (MAE/USP), e com a conservação. Com o suporte da museologia no que tange à cadeia operatória de procedimentos de salvaguarda, os profissionais da arqueologia, museólogas/os e conservadoras/es podem, de forma colaborativa, implementar ações adequadas e adaptadas à gestão das grandes coleções arqueológicas que se encontram nas reservas técnicas. Essa necessária interface tem sido abordada por profissionais da museologia e da conservação, como Carlos Costa $(2007,2008)$, Camila Moraes Wichers (2010), Mara Vasconcelos (2011), Ana Paula Leal (2011, 2014), Diego Ribeiro (2012), Luciana Ballardo (2013), Silvia Lima (2016), Grasiela Toledo (2017), dentre outras/os.

Nessa perspectiva e preocupadas/os com a situação do nosso acervo arqueológico, passamos, em 2013, a direcionar as ações para sua salvaguarda, focando os esforços na gestão. Embora a Instituição não contasse com museólogas/os e conservadoras/es, encontramos apoio na contratação de estagiários do Curso de Museologia da UFRGS, na literatura disponível e em muitos estudos e conversas com os pares ${ }^{15}$. Deparamo-nos com a seguinte situação:

- Documentação museológica até então inexistente, como o inventário de objetos.

- Degradação de materiais por agentes biológicos (couro e madeira), exsudação (vidro, couro e de origem vegetal), oxidação (metal).

- Inadequação das condições ambientais (temperatura e umidade relativa) dos dois espaços onde o acervo estava depositado.

Essa realidade demandou um olhar e atitudes direcionadas à preservação do acervo arqueológico, alicerçadas nas orientações, num primeiro momento, da conservação preventiva. Essa área aplica procedimentos que objetivam o controle dos agentes de degradação, visando evitá-los ou minimizar os danos às coleções museológicas (PEDERSOLI JR.; MATTOS, 2013). As publicações denominadas Tópicos em Conservação Preventiva, editadas pelo Laboratório de Ciência da Conservação/Escola de Belas Artes (LACICOR/EBA), da Universidade Federal de Minas Gerais (UFMG), foram fundamentais nesse processo, dentre elas os Tópicos 1 (SOUZA et al., 2008), 3 (FRONER; SOUZA, 2008) e 4 (SOUZA; FRONER, 2008). Segundo Froner e Souza (2008, p. 3), "a conservação dos bens culturais pode ser compreendida como o conjunto de esforços para prolongar ao máximo a existência dos objetos a partir de intervenções conscientes e controladas no ambiente externo ao objeto, como também de intervenções diretas no objeto."

A conservação preventiva relacionada a acervos arqueológicos tem, de maneira mais expressiva nos últimos anos, conquistado espaço na literatura produzida no Brasil.

\footnotetext{
14 No período compreendido entre 2011 e 2016, o arqueólogo Fabricio J. Nazzari Vicroski foi contratado pela Coordenação da Memória Cultural da SMC para trabalhar com a demanda dos processos de licenciamento ambiental, junto à Equipe do Patrimônio Histórico e Cultural (EPAHC/SMC). No momento, não há arqueóloga/o na Prefeitura de Porto Alegre para assumir a função relacionada à arqueologia preventiva.

${ }^{15}$ Ingressei como aluna do Curso de Museologia da UFRGS para cursar as disciplinas de Conservação e de Documentação, o que foi fundamental para iniciar a nova etapa de trabalho com o acervo arqueológico.
} 
Instituições como o Museu Nacional/UFRJ (LIMA; RABELLO, 2007, p. 245-273), o Museu Arqueológico de Sambaqui de Joinville (SANTOS, 2014), o Laboratório Multidisciplinar de Investigação Arqueológica/Lâmina/UFPel (LEAL, 2014), o Museu de Arqueologia e Etnologia/USP, o Museu de Arqueologia e Etnologia/UFBA, o Laboratório de Arqueologia Peter Hilbert/Núcleo de Pesquisa Arqueológica do IEPA, entre outras, têm desenvolvido programas de salvaguarda e aplicado medidas para a conservação das coleções arqueológicas ${ }^{16}$.

Nessa direção, iniciamos com a elaboração do Diagnóstico de Conservação Preventiva do Acervo Arqueológico, em 2014 ${ }^{17}$, abordando as condições ambientais nos níveis macro, médio e micro e suas influências nos objetos arqueológicos. Foi dada ênfase aos dois últimos níveis, considerando o espaço em que se encontrava a Coleção Arqueológica e ao meio que estava em contato direto com os objetos. As reflexões resultantes desse trabalho forneceram a base para a tomada de decisões quanto aos procedimentos que deveriam ser adotados visando à preservação dos bens culturais ${ }^{18}$.

O produto dessa etapa foi a redação da primeira versão do Manual de Conservação Preventiva, em 2015, implementando, no espaço do setor de arqueologia, uma área de guarda e de trabalho mais adequada à conservação preventiva do acervo. A última versão do documento, de $2018^{19}$, incluiu procedimentos presentes na Portaria $n^{\circ} 196$, publicada em 18 de maio de 2016 pelo IPHAN, a qual dispõe sobre a conservação de bens arqueológicos móveis. O Manual apresenta os seguintes itens, os quais, por sua vez, são subdivididos em vários subitens:

- O ambiente - Setor de Arqueologia: 1 - Monitoramento e controle climático; 2 Segurança; 3 - Proteção à radiação luminosa; 4 - Proteção à contaminação por agentes biológicos e poluentes; 5 - Controle da ventilação; 6 - Manutenção e limpeza.

- O ambiente - Espaços Expositivos: 1 - Monitoramento e controle da umidade relativa, temperatura e luminosidade dos suportes expositivos.

- A Coleção Arqueológica: 1 - Higienização dos objetos; 2 - Manuseio dos objetos; 3 Marcação dos objetos; 4 - Embalagem dos objetos; 5 - Acondicionamento das subcoleções; 6 - Armazenamento das subcoleções; 7 - Monitoramento das condições de conservação e documentação da Coleção Arqueológica; 8 - Reorganização preliminar ao inventário museológico; 9 - Transporte.

Nesse mesmo período foi formalizada a concessão de Endossos Institucionais a projetos de pesquisa arqueológica com a publicação, no Diário Oficial de Porto Alegre, da Instrução Normativa $1 / 2015^{20}$, a qual estabelece diretrizes para a Emissão de Endossos Institucionais para guarda de remanescentes arqueológicos no Museu de Porto Alegre Joaquim Felizardo. O Museu concede endossos desde a década de 1990, comprometendo-se com a salvaguarda dos materiais recuperados e patrimonializados, cumprindo as exigências da Portaria $n^{\circ}$ 07, de 01 de dezembro de 1988, e da Instrução Normativa $\mathrm{n}^{\circ}$ 01, de 25 de março de 2015, ambas publicadas pelo IPHAN.

Outros dois documentos elaborados pela Instituição apresentam as normas e obrigações que devem ser atendidas para a concessão do Endosso Institucional - o Termo

\footnotetext{
${ }^{16}$ Com exceção, no momento, do Museu Nacional que perdeu grande parte do seu acervo arqueológico no incêndio de grandes proporções que acometeu a edificação, tragicamente, em 2018.

${ }^{17}$ Acessível em http://www.museudeportoalegre.com/documentos-2/. Data de acesso: 05/12/2020.

18 O trabalho realizado entre 2013 e 2014 contou com a fundamental e investigativa participação do estagiário, então acadêmico do Curso de Museologia da UFRGS, Arthur Becker (nosso 'professor Pardal').

${ }^{19}$ Acessível em http://www.museudeportoalegre.com/documentos-2/. Data de acesso: 05/12/2020.

${ }^{20}$ Acessível em http://www.museudeportoalegre.com/documentos-2/. Data de acesso: 05/12/2020.
} 
de Responsabilidade para Concessão de Endosso Institucional e o Protocolo de Ingresso de Acervos Arqueológicos ${ }^{21}$. No primeiro, assinam a/o profissional da arqueologia e a/o empreendedora/or, no caso de pesquisa arqueológica ligada ao licenciamento ambiental. Quanto ao Protocolo, a primeira versão elaborada em 2016 foi atualizada em 2018, após a publicação de um artigo escrito coletivamente com as/os profissionais do Museu e do Laboratório Multidisciplinar de Investigação Arqueológica (LÂMINA/UFPel) (SALLÉS et al., 2018), e está de acordo com a Portaria no 196 do IPHAN, mencionada anteriormente.

O Protocolo de Ingresso de Acervos Arqueológicos regula as condições do material e da documentação a serem entregues para guarda. Apresenta a documentação que deve ser gerada e os procedimentos que devem ser adotados quanto à salvaguarda dos acervos, a qual é assumida pelo Museu no momento de seu recebimento. O Protocolo respeita as normatizações da Portaria do IPHAN n. 07 de 1988 e da Instrução Normativa n.01 de 2015 e as recomendações da Portaria do IPHAN n. 196 de 2016. Esse documento foi elaborado de acordo com o Manual de Conservação Preventiva e com as práticas de documentação museológica do acervo arqueológico. O Termo de Responsabilidade para Concessão de Endosso Institucional apresenta normas que complementam o Protocolo.

O Protocolo contempla os seguintes aspectos:

- Quanto à documentação: documentação necessária e os passos a serem seguidos para a concessão de Endosso Institucional pelo Museu, bem como informações que devem constar no projeto de pesquisa; documentação a ser entregue quando do ingresso do acervo arqueológico na Instituição - documentos primários, relatórios, dossiê de conservação preventiva, etc;

- Quanto à gestão do material arqueológico em campo: critérios de triagem de materiais, conservação preventiva, embalagem, transporte, etc;

- Quanto à gestão do material arqueológico em laboratório: higienização, manuseio, identificação, colagem, estabilização, conservação preventiva e/ou curativa, embalagem, acondicionamento, etc;

- Quanto aos objetos que se encontrarem em situação de fragilidade, com presença de patologias e/ou vulneráveis a processos de deterioração;

- Quanto à coleta de amostras;

- Entrega do acervo arqueológico no Museu.

O Protocolo ainda aponta que devem ser previstas reuniões de trabalho com a equipe técnica do Museu durante os trabalhos de campo e de laboratório visando o acompanhamento dos procedimentos de triagem de materiais arqueológicos; que, dentre os materiais recuperados, devem ser indicados aqueles que poderão compor o Acervo de Referência do sítio arqueológico (ou da subcoleção); e que os critérios para indicação devem ser discutidos com a equipe técnica do Museu. Tal documento salienta ainda a exigência de projetos que contribuam para a construção do conhecimento sobre Porto Alegre e de entrega de artigo científico.

A Portaria $n^{\circ} 196$ do IPHAN, mencionada anteriormente, coloca o prazo de doze meses, a contar da data de sua publicação, para as Instituições se adequarem ao seu conteúdo. O Museu recebeu vistoria técnica de servidores da Superintendência do IPHAN do Rio Grande do Sul no segundo semestre de 2016 para verificação se o mesmo estava apto a ser mantido no Cadastro Nacional de Instituições de Guarda e Pesquisa. Foram feitas exigências com relação ao acondicionamento do acervo; à proteção quanto

${ }^{21}$ Acessível em http://www.museudeportoalegre.com/documentos-2/. Data de acesso: 05/12/2020. 
à luminosidade natural; e que o espaço destinado ao acervo fosse exclusivo a esse fim. Até então o espaço de guarda era compartilhado com o de gabinete e de laboratório no pavimento térreo da edificação. Já estávamos reorganizando a área do acervo desde 2013, bem como o seu acondicionamento e armazenamento a partir das orientações do Manual de Conservação Preventiva. Sendo assim, as exigências do IPHAN prontamente foram cumpridas, inclusive a transferência do trabalho de gabinete para uma sala ao lado da área do acervo em 2018 (Figuras 2 e 3$)^{22}$.

Figura 2 - Imagem de parte do armário deslizante na Reserva Técnica da Coleção Arqueológica, em direção às estantes metálicas, pavimento térreo. Fotografia: Clarice Alves (2020).

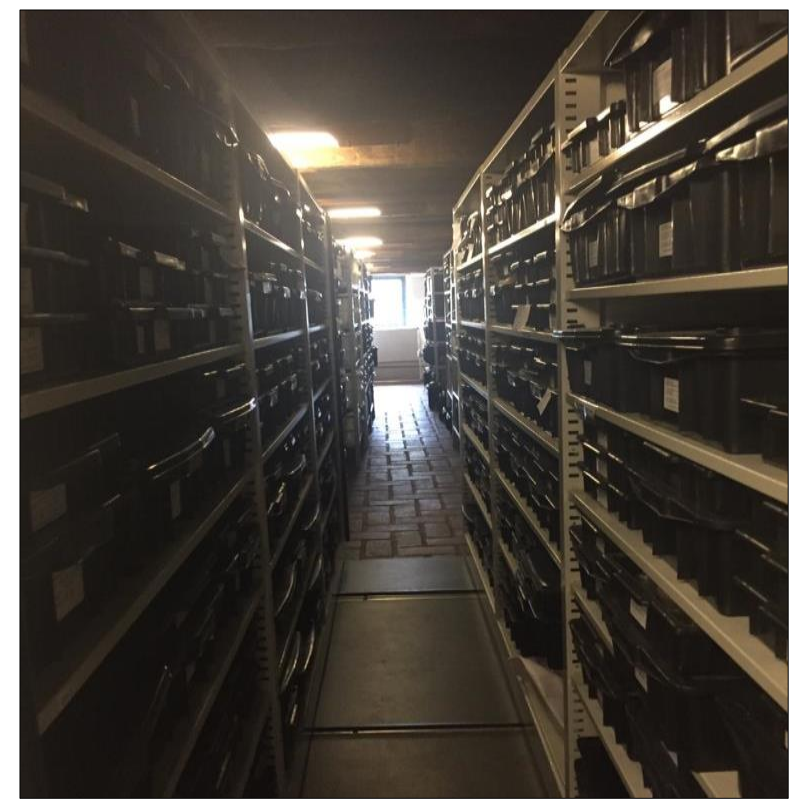

O Museu tem feito muitos esforços para que um novo prédio seja construído para abrigar todas as suas coleções em reservas técnicas qualificadas. Enquanto isso não ocorre, os desafios são diários, considerando que a sede do Museu é um solar de meados do século XIX, com muita umidade ascendente e oriunda do ambiente do entorno, com piso inadequado, entre outros aspectos. Uma das vantagens é que suas paredes são espessas $(60 \mathrm{~cm})$, o que mantém a temperatura com certa estabilidade em seu interior. Outra questão é a diversidade de tipos de materiais, o que demandaria cuidados de controle ambiental diferenciados. Sem espaço suficiente e considerando que o melhor não seria dissociar objetos de um mesmo sítio arqueológico, permanecemos com o desafio de tentar implementar procedimentos de conservação preventiva que minimizem a sua degradação.

$\mathrm{O}$ enfrentamento do problema quanto à salvaguarda do acervo arqueológico teve sequência com a definição sobre a documentação museológica ainda em 2015, após a elaboração da primeira versão do Manual de Conservação Preventiva. Trabalhar a gestão documental de pesquisas e de acervos arqueológicos se apresentou como um grande desafio. Reflexões sobre a sua pertinência e práticas são recentes, pouco divulgadas. Até há pouco tempo, as/os arqueólogas/os, incluindo eu, estavam voltadas/os, na sua grande maioria, a questões relacionadas aos estudos arqueológicos de campo, de laboratório e de

\footnotetext{
22 Em 2016, o setor de arqueologia do Museu passou a contar com a colega Clarisse Alves, técnica em cultura transferida de outro equipamento da SMC. Foi um grande presente ter uma parceira de trabalho e que, neste momento, está responsável pela gestão da Coleção Arqueológica.
} 
gabinete. Com a bagagem trazida pelas experiências e o redirecionamento das práticas no Museu, nos propomos a pensar formas de relacionar as documentações arqueológica e museológica. A importância da documentação sobre os sítios arqueológicos, fundamental para a contextualização dos objetos tornados acervos museológicos, tem sido colocada por autores como Costa (2007), Ramos (2011), Ballardo (2013) e Leal (2014).

Figura 3 - Imagem das estantes metálicas em direção ao armário deslizante na Reserva Técnica da Coleção Arqueológica, pavimento térreo. Fotografia: Clarice Alves (2020).

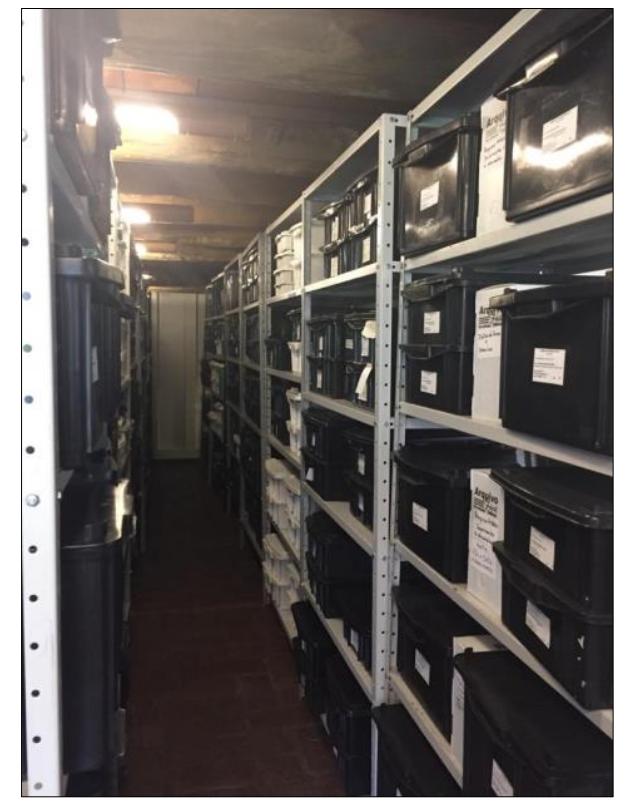

A partir dessa preocupação, na etapa de elaboração das fichas de entrada, guarda e saída do acervo arqueológico, delineamos a estrutura da organização dessa documentação ${ }^{23}$.

O acervo passou a compor a Coleção Arqueológica, a qual, por sua vez, é subdividida em subcoleções formadas pelos materiais provenientes de cada sítio e de ocorrência arqueológica. Cada subcoleção é constituída pelo Acervo de Pesquisa, a partir do qual é selecionado o Acervo de Referência ${ }^{24}$. O primeiro se refere a todo o conjunto dos materiais identificados por categorias materiais e suas especificidades, como por exemplo: louça (porcelana, faiança fina, faiança, etc); metal (ferro, cobre, etc.); e cerâmica (simples, vidrada, indígena/Guarani, matriz africana). O segundo é composto pelos objetos escolhidos segundo critérios estabelecidos para inventário.

Desde o início do processo, uma das preocupações era relacionada ao inventário museológico. Para refletirmos sobre a necessidade de inventariar a Coleção Arqueológica do Museu e sobre como fazê-lo, é importante analisar e avaliar a natureza e as condições do patrimônio arqueológico recuperado. $\mathrm{O}$ acervo é composto por materiais oriundos, preponderantemente, de sítios urbanos. Tendo em vista a intensa, dinâmica e contínua

\footnotetext{
${ }^{23}$ A elaboração de toda a documentação museológica nos meios digital e físico, em 2015, contou com a compromissada, séria e disciplinada participação do estagiário, então acadêmico do Curso de Museologia da UFRGS, Wellington Ricardo Machado da Silva.

${ }^{24}$ A divisão da subcoleção em Acervo de Pesquisa e Acervo de Referência tomou como orientação o trabalho realizado com os acervos recuperados por ocasião da pesquisa arqueológica no âmbito da instalação da Ferrovia Transnordestina. Segundo Camila Witchers (2010), a salvaguarda dos acervos foi desenvolvida segundo duas perspectivas: Coleções de Referência e Acervo de Pesquisa.
} 
ocupação do espaço urbano, os arqueólogos deparam-se cotidianamente com uma abundância de estruturas e artefatos evidenciados nas mais distintas circunstâncias. $\mathrm{O}$ consumo de massa, com início já no século XIX, resulta em práticas de descarte de grande quantidade de materiais que vem a formar as lixeiras - sejam domésticas, coletivas, hospitalares, industriais, etc. -, além das camadas de aterros com refugos. Discussões sobre o que deve ser coletado e registrado para compor os acervos das diferentes instituições colocam os profissionais frente a dilemas que envolvem desde espaço físico dos laboratórios e reservas técnicas e condições de conservação até questões de ordem ética. Essas questões tem sido tema de debates em vários encontros científicos entre os profissionais da arqueologia.

Considerando o colocado e que a grande maioria dos objetos se encontra fragmentada no momento de sua coleta e que, principalmente em meios urbanos, os depósitos são secundários - isto é, não são encontrados em seu local de origem, de uso definimos que somente uma amostra da subcoleção deveria ser inventariada. Para isso, estabelecemos critérios norteadores, os quais podem ser considerados individualmente ou relacionados entre si. São eles:

1) Objeto que esteja de acordo com a política de aquisição do Museu;

2) Objeto que, enquanto unidade pertencente a um conjunto de peças ou não, seja fundamental ou de grande relevância para interpretações arqueológicas, futuras pesquisas e/ou comunicação, através de exposições, ações educativas, publicações, entre outros;

3) Objeto que possua característica(s) estética(s) singular(es) e/ou que seja constatado como raro no conjunto dos demais da mesma subcoleção ou da Coleção Arqueológica;

4) Objeto que, através de sua materialidade, consiga representar os demais pertencentes à mesma subcoleção em sua categoria material específica;

5) Objeto que tenha sido produzido e/ou manipulado por grupos sociais minoritários, podendo ser-lhe atribuído(s) significado(s) por meio de diferentes categorias, como étnica, simbólica, de gênero, de trabalho, etc;

6) Objeto que comunique sobre práticas econômicas, sociais, étnicas, religiosas, entre outras, relacionadas à história de Porto Alegre, e que compartilhe de outros critérios para inventário;

7) Objeto que se encontre em estado de conservação bom ou regular ou, se ruim, possa receber ações de conservação curativa.

Em 2017, com o trabalho de documentação museológica em sua fase inicial, vislumbramos a possibilidade de tornar a Coleção Arqueológica acessível ao público. Com a utilização, pela Prefeitura de Porto Alegre, do Sistema Pergamum - um banco de dados para documentação de bibliotecas, museus e arquivos -, tornou-se viável a adoção de um instrumento informatizado de gerenciamento digital da Coleção. O SGEIA, mencionado anteriormente, foi concebido com a preocupação de gestão das informações relacionadas, principalmente, aos sítios, ocorrências e materiais arqueológicos em geral, às pesquisas e aos processos do licenciamento ambiental. $\mathrm{Na}$ época do seu desenvolvimento, entre 2006 e 2008, não havia museólogas/os trabalhando no Museu, e o foco do setor de arqueologia se restringia à documentação arqueológica. Assim, infelizmente e por falta de competência na área, não soubemos aproveitar a oportunidade e desenvolver um sistema que também contemplasse as informações sobre a Coleção Arqueológica sob a perspectiva da documentação museológica. 
Nesse processo, foi necessário adequar o Pergamum às especificidades do tipo de acervo, o que foi realizado com a equipe da Prefeitura Municipal destinada a esse fim. $\mathrm{O}$ objetivo era dispor, em um único sistema, de uma ferramenta de acesso público para pesquisa e de documentação museológica e arqueológica para gestão institucional. Entre suas vantagens, vislumbramos a possibilidade de integração, a partir de palavras-chave, de todas as coleções do Museu - as Coleções Fotográfica e Tridimensional em fase de alimentação ${ }^{25}$. Com base nas documentações de entrada, guarda e saída definidas anteriormente, considerando a perspectiva de integrar a documentação museológica e a arqueológica, elaboramos as fichas de dados do sítio arqueológico, da subcoleção (Acervo de Pesquisa) e do objeto inventariado (Acervo de Referência). No entanto, o Sistema Pergamum apresentou um limite justamente no aspecto que mais nos entusiasmava, que era o de tornar acessíveis e integradas as informações dos dois tipos de documentações, além da listagem de sítios e de subcoleções. Tendo em vista a interface do Pergamum para museus, as fichas dos sítios e das subcoleções não podem ser acessíveis ao público, somente a dos objetos. A solução encontrada foi anexar tais fichas em PDF, assim como as listagens das caixas e fichas das caixas de armazenamento dos materiais ${ }^{26}$. Nas palavras de Costa (2007), as fichas sobre os sítios arqueológicos e as subcoleções poderiam ser consideradas como instrumentos documentais complementares ao acervo ou como uma 'documentação paralela', 'auxiliar'.

É importante salientar que o que foi exposto até aqui, relacionado à documentação museológica, se encontra em processo de implementação. Tal processo teve início em 2015, com a documentação das primeiras subcoleções que deram entrada no Museu em 1993, provenientes de sítios arqueológicos pesquisados pela instituição. A alimentação do Pergamum, por sua vez, iniciou em 2018. Considerando que a Coleção Arqueológica é de grandes proporções e que o trabalho de documentação requer uma equipe de profissionais, a perspectiva é a de que serão necessários muitos anos pela frente para concluir essa tarefa com o acervo sob guarda do Museu. Com o Protocolo de Ingresso de Acervos Arqueológicos, instituído em 2016, parte da documentação já deve ser realizada no âmbito do projeto de pesquisa ao qual a Instituição concedeu endosso, agilizando e otimizando o trabalho do setor de arqueologia.

$\mathrm{O}$ até agora exposto, de maneira sucinta, a respeito da trajetória da formação da Coleção Arqueológica do Museu e as estratégias implementadas para sua salvaguarda, mostram que o foco das atenções do setor de arqueologia passou a ser, nos últimos anos, a gestão do acervo, considerando o seu crescimento, a sua diversidade e a responsabilidade da Instituição pela sua guarda legal e preservação. Além disso, a Coleção possui um grande potencial para sua extroversão, através de exposições e ações educativas. Ela também pode ser utilizada como recurso para reflexões e lutas, tendo em vista que nela estão contemplados diferentes grupos socioculturais. Questões étnicas, de gênero, de trabalho, de resistências e permanências na vida cotidiana estão presentes na cultura material recuperada nas áreas de ocupação humana do período pré-colonial ao século XX. É preciso sempre incentivar e dar ênfase à pesquisa do acervo arqueológico para que o mesmo possa contribuir para o conhecimento sobre a cidade onde habitamos, sobre nós mesmos, sobre quem somos e para onde vamos. A pesquisa arqueológica em sítios urbanos, neste sentido, por estar inserida no dia a dia da cidade, tão próxima dos

\footnotetext{
${ }^{25}$ Orientação da museóloga Maria Cristina Oliveira Bruno (MAE/USP) em uma consultoria ao Museu de Porto Alegre Joaquim Felizardo.

${ }^{26}$ Os trabalhos de reorganização física da Coleção Arqueológica, segundo o Manual de Conservação Preventiva, e de adequação do sistema Pergamum ao acervo contou com a ativa, dedicada e compromissada participação da estagiária, então acadêmica do Curso de História da UFRGS, Bibiana Santos Domingues.
} 
habitantes no espaço e no tempo, pode ser empregada como um instrumento de construção de sujeitos sociais.

Por outro lado, o contexto de inserção das práticas arqueológicas na cidade se transformou. O Museu deixou de ser o principal agente de pesquisas de campo e de laboratório em Porto Alegre e de atuar como gestor do patrimônio arqueológico municipal, no sentido de uma gestão preventiva. Com essas práticas, foi possível conhecer e preservar esse patrimônio, construindo bases mais sólidas para uma atuação no presente e no futuro. A partir das experiências, dos acertos e erros, e com mais maturidade, o Museu está tendo condições de qualificar seu trabalho de gestão do acervo que vem sendo recuperado e inseri-lo no redirecionamento das suas ações na perspectiva de um Museu de Cidade.

\section{AGRADECIMENTOS}

Agradeço às/aos colegas do Museu de Porto Alegre Joaquim Felizardo e a todas/os parceiras/os de trabalho e de pesquisas que, juntas/os, construímos uma arqueologia da nossa cidade. Sou muito grata pela oportunidade de participar dessa trajetória e de ter me tornado arqueóloga, de fato, ao longo dos 26 anos em que trabalhei na Instituição.

Agradeço, especialmente, a Leticia Bauer, Diretora do Museu de Porto Alegre Joaquim Felizardo no período em que me aposentei, e a Clarice Alves, minha colega do setor de arqueologia e atual gestora da Coleção Arqueológica, pelas ricas contribuições que fizeram a este texto. 


\section{REFERÊNCIAS BIBLIOGRÁFICAS}

ALVES, Clarice da Silva. Quando ela pinta as unhas: vestígios arqueológicos da mulher moderna na Porto Alegre dos anos 1940. TCC (Curso de Especialização em Arqueologia e Patrimônio) - PUCRS, Porto Alegre, 2017.

BALLARDO, Luciana Oliveira Messeder. Documentação museológica: a elaboração de um sistema documental para acervos arqueológicos e sua aplicação no Laboratório de Estudos e Pesquisas Arqueológicas. Dissertação (Mestrado em Patrimônio Cultural) - UFSM, Santa Maria, 2013.

BARETTA, Jocyane Ricelly. Beleza, vaidade e estética através da cultura material na Porto Alegre oitocentista. TCC (Bacharelado em História) - ULBRA. Canoas, 2009, 107p.

BARETTA, Jocyane Ricelly. Arqueologia e a construção de memórias materiais da ditadura militar em Porto Alegre/RS (1964/1985). Dissertação (Mestrado em História) - UNICAMP. Campinas, 2015, 193p.

BARETTA, Jocyane Ricelly. Uma arqueologia do inferno. Misoginia e feminização através do aparato material da Ditadura em Porto Alegre/RS (1964/1985). Tese (Doutorado em Arqueologia) - UFPel, Pelotas, 2020.

BAUER, Leticia Brandt. Museu de quem? Museu para quem? Experiências do Museu de Porto Alegre Joaquim Felizardo. Anais da Semana dos Museus da UFPel. 2015/2016/2017, Pelotas: Editora da UFPel, 2018, p. 148-155.

BITENCOURT, Daiane Brum. Para sua saúde e vigor: práticas de cura e medicamentos populares em Porto Alegre (1776-1936). Dissertação (Mestrado em História) - PUCRS. Porto Alegre, 2011, $154 \mathrm{p}$.

BRANCHELLI, Fabiano Aiub. Vida material e econômica da Porto Alegre oitocentista. Dissertação (Mestrado em História) - PUCRS. Porto Alegre, 2007.

CARLE, Cláudio. Assentamentos negros no Rio Grande do Sul. A organização espacial dos assentamentos de ocupação tradicional de africanos e descendentes no Rio Grande do Sul, nos séculos XVIII e XIX. Tese (Doutorado em Arqueologia) - PUCRS. Porto Alegre, 2005.

CAZZETTA, Miriam. Arqueologia e Planejamento Urbano. Anais do $1^{\circ}$ Congresso Latino-Americano sobre a Cultura Arquitetônica e Urbanística. Porto Alegre, 1991 p.190-196.

COMPANY, Zeli Teresinha. Procurando bem todo mundo tem pereba: práticas e recursos de cura a partir da cultura material na Porto Alegre do século XIX (1815-1898). Tese (Doutorado em História) PUCRS. Porto Alegre, 2011, 284p.

COSTA, Carlos Alberto Santos. Proposta de instrumento documental museológico complementar para as coleções arqueológicas do MAE/UFBA. Revista Eletrônica Jovem Museologia: estudos sobre museus, museologia e patrimônio, n.4, 2007.20p.

COSTA, Carlos Alberto Santos. A materialidade de uma relação interdisciplinar. Revista Museu. Postado em 30 de dezembro de 2008 \13:26 por Editoria RM, 2008.

FRAGA, Rodrigo Garcia. A ocupação do século XX: um novo olhar sobre o Solar Lopo Gonçalves. Dissertação (Mestrado em História) - UFGRS, Porto Alegre, 2017.

FRONER, Yaci-Ara; SOUZA, Luiz Antônio Cruz. Preservação de bens patrimoniais: conceitos e critérios. Tópicos em Conservação Preventiva - 3. Belo Horizonte:LACICOR-EBA-UFMG, 2008. $22 \mathrm{p}$.

JULIANI, Lucia de Jesus de C. A cartografia arqueológica como instrumento de planejamento urbano: o caso de São Paulo. Anais do $4^{o}$ Encontro Nacional de Estudos sobre o Meio Ambiente. Cuiabá: ICHS- UFMT, 1993.

LAZZAROTTI, Marcelo dos Santos. 2013. Arqueologia da margem. Porto Alegre: a formação de uma cidade portuária (do século XVIII a meados do século XIX). Dissertação (Mestrado em História) PUCRS. Porto Alegre, 254p. 
LEAL, Ana Paula da Rosa. Musealização da Arqueologia: Documentação e Gerenciamento no Museu de Arqueologia e Etnologia da Universidade Federal do Paraná. TCC (Bacharelado em Museologia) UFPel, Pelotas, 2011.

LEAL, Ana Paula da Rosa. Arqueologia, Museologia e Conservação: Documentação e Gerenciamento da Coleção proveniente do Sítio Santa Bárbara (Pelotas-RS). Dissertação (Mestrado em Antropologia) - UFPel, Pelotas, 2014.

LIMA, Silvia Cunha. A conservação de cerâmicas arqueológicas da Amazônia. Cerâmicas arqueológicas da Amazônia: rumo a uma nova sintese / Cristiana Barreto, Helena Pinto Lima, Carla Jaimes Betancourt, organizadoras. Belém: IPHAN/MINC, 2016, p. 543-550.

LIMA, Tania Andrade; RABELLO, Angela Maria C. Coleções arqueológicas em perigo: o caso do Museu Nacional da Quinta da Boa Vista. In: Patrimônio Arqueológico: o desafio da preservação / Tania Andrade Lima organizadora. Revista do Patrimônio, n. 33, 2007, p.245-273.

MORAES WICHERS, Camila A. de. Museus e Antropofagia do Patrimônio Arqueológico: (des) caminhos da prática brasileira. Tese (Doutorado em Museologia) - Universidade Lusófona de Humanidades e Tecnologias, Lisboa, 2010.

MORAES, Gabriela Longo. Cerâmica Histórica: algumas considerações. Estudo de caso da coleção cerâmica do sítio Solar Lopo Gonçalves, RS.JA-04. TCC (Bacharelado em Arqueologia). - FURG, Rio Grande, 2015, 57p.

NUNES, Daniel Minossi. Nos bares, cafés e restaurantes de Porto Alegre: cultura material e o ideário moderno em meados do século XX. Dissertação (Mestrado em Antropologia) - UFPel. Pelotas, 2014, 199p.

OLIVEIRA, Alberto Tavares Duarte de. Um Estudo em Arqueologia Urbana: a carta de potencial arqueológico do Centro Histórico de Porto Alegre. Dissertação (Mestrado em História) - PUCRS. Porto Alegre, 2005, 242p.

OLIVEIRA, Alberto; TOCCHETTO, Fernanda; BARROSO, Vera L. M.; COMPANY, Zeli T. A Arqueologia vai ao Hospital. Pesquisa arqueológica para a implantação do Centro Histórico-Cultural Santa Casa. Porto Alegre: Faculdade Porto-Alegrense/ISCMPA, 2009, 95p.

PEDERSOLI JR, José Luiz;. MATTOS, Lorete. O gerenciamento de riscos em acervos. Preservação de Patrimônio Cultural. Porto Alegre: Museu da UFRGS, Setor de Patrimônio Histórico da UFRGS, Prefeitura Municipal de Porto Alegre, Associação de Conservadores e Restauradores de Bens Culturais do Rio Grande do Sul, 2013.

POSSAMAI, Zita Rosane. Nos bastidores do Museu: Patrimônio e passado da cidade de Porto Alegre. Porto Alegre: EST edições, 2001.

PREFEITURA MUNICIPAL DE PORTO ALEGRE/ SECRETARIA MUNICIPAL DA CULTURA. Regimento interno do Museu de Porto Alegre Joaquim José Felizardo. Diário Oficial do Municipio de Porto Alegre. Disponível em: http://dopaonlineupload.procempa.com.br/ dopaonlineupload/364_ce_27228_3.pdf. Acesso: 14 nov. 2017.

RAMOS, Rafaela Nunes. Políticas de preservação para acervos arqueológicos. Cadernos do LEPAARQ - Textos de Antropologia, Arqueologia e Patrimônio. V. VIII, $n^{\circ} 15 / 16$. Pelotas, RS: Editora da UFPEL, 2011, p. 11-26.

RIBEIRO, Diego Lemos. A Musealização da Arqueologia: um estudo dos Museus de Arqueologia do Xingó e do Sambaqui de Joinville. Tese (Doutorado em Arqueologia) - MAE/USP, São Paulo, 2012.

SALLÉS, Jaime Mujica; TOCCHETTO, Fernanda Bordin; DODE, Susana dos Santos; SOUZA, Taciane Silveira; SILVA, Fabio Barreto da; DUTRA, Márcia Regina Ribeiro; MEDEIROS, Eneri James Borges; ALVES, Clarice da Silva; DOMINGUES, Bibiana Santos. Protocolo de ingresso de acervos arqueológicos em instituições de guarda e pesquisa: uma proposta do Lâmina/UFPel e do Museu de Porto Alegre Joaquim Felizardo - RS. Rev. Arqueologia Pública, Campinas, SP v.11 n.2 p. Novembro/2017. 
SANTOS, Adriana Maria Pereira dos. A Conservação dos Acervos no Museu Arqueológico de Sambaqui de Joinville - MASJ. Cadernos do CEOM - Museus: pesquisa, acervo, comunicação. Ano 18, n. 21. p. 227-242, 2014.

SANTOS, Paulo Alexandre da Graça. Contentores de bebidas alcoólicas: usos e significados na Porto Alegre oitocentista. Dissertação (Mestrado em História) - PUCRS. Porto Alegre, 2005, 242p.

SANTOS, Paulo Alexandre da Graça. Mensagens nas garrafas: o prático e o simbólico no consumo de bebidas em Porto Alegre (1875-1930). Tese (Doutorado em História) - PUCRS. Porto Alegre, 2009, 296p.

SOUZA, Luiz Antônio Cruz; FRONER, Yaci-Ara. Reconhecimento de materiais que compõe acervos. Tópicos em Conservação Preventiva - 4. Belo Horizonte:LACICOR-EBA-UFMG, 2008. $31 \mathrm{p}$.

SOUZA, Luiz Antônio Cruz; ROSADO, Alessandra; FRONER, Yaci-Ara (organização). Roteiro de Avaliação e Diagnóstico em Conservação Preventiva. Tópicos em Conservação Preventiva - 1. Belo Horizonte:LACICOR-EBA-UFMG, 2008. 43p.

SYMANSKI, Luis Cláudio P. Espaço privado e vida material em Porto Alegre no século XIX. Porto Alegre. EDIPUCRS, 1998, 276p.

TATSCH, Juliana Pozzo. Arqueologia da escravidão em um sítio rural na Porto Alegre oitocentista: as relações espaciais e materiais no sitio RS.JA-74. Dissertação (Mestrado em Antropologia) - UFPel. Pelotas, 2015, 143p.

TEMIÑO, Ignácio R. Arqueologia Urbana em España. Barcelona: Editorial Ariel, 2004.

THIESEN, Beatriz V. As paisagens da cidade: Arqueologia da área central da Porto Alegre do século XIX. Dissertação (Mestrado em História) - PUCRS. Porto Alegre, 1999, 344p.

THIESEN, Beatriz V. Fábrica, identidade e paisagem urbana: arqueologia da Bopp Irmãos (19061924). Tese (Doutorado em História) - PUCRS. Porto Alegre, 2005, 272p.

TOCCHETTO, Fernanda Bordin; SYMANSKI, Luis Cláudio Pereira; SANTOS, Shirlei Martins dos. Programa de Arqueologia Urbana do Município de Porto Alegre, RS. Revista do CEPA, v.23, n.30 (jul.-dez.1999), Santa Cruz do Sul: Editora da UNISC, 2000, p.75-101.

TOCCHETTO, Fernanda; SYMANSKI, Luis C.; OZÓRIO, Sergio R.; OLIVEIRA, Alberto T. D. de; CAPPELLETTI, Angela M. A faiança fina em Porto Alegre: vestígios arqueológicos de uma cidade. Porto Alegre: Unidade Editorial da Secretaria Municipal da Cultura de Porto Alegre, 2001, $168 \mathrm{p}$.

TOCCHETTO, Fernanda B. Fica dentro ou joga fora? Sobre práticas cotidianas em unidades domésticas na Porto Alegre oitocentista. Tese (Doutorado em História) - PUCRS, Porto Alegre, 2004, 325p.

TOCCHETTO, Fernanda. Fica dentro ou joga fora? Sobre práticas cotidianas na Porto Alegre moderna oitocentista. São Leopoldo: Oikos, 2010.

TOCCHETTO, Fernanda B. O Museu de Porto Alegre Joaquim Felizardo e sua atuação na arqueologia da cidade. Gerenciamento do patrimônio cultural no âmbito do licenciamento ambiental em Porto Alegre [recurso eletrônico] : o componente arqueológico / [organização] Luiz Antônio Bolcato Custódio. Porto Alegre: Editora da Cidade, 2016, p. 33-44.

TOLEDO, Grasiela Tebaldi. Musealização da Arqueologia e Conservação arqueológica: experiências e perspectivas para a preservação patrimonial. Tese (Doutorado em Arqueologia) - MAE/USP, São Paulo, 2017.

VASCONCELOS, Mara Lúcia Carrett de. O conservador na gestão de acervos arqueológicos: um estudo de caso do sítio Guarani PS-03 Totó (RS-Brasil). TCC (Bacharelado em Conservação e Restauro de Bens Culturais Móveis) - UFPel, Pelotas, 2011. 